\title{
Psychosocial concerns reported by Syrian refugees living in Jordan: systematic review of unpublished needs assessments
}

\author{
Ruth Wells, Zachary Steel, Mohammad Abo-Hilal, Abdul Halim Hassan and Catalina Lawsin
}

\section{Background}

Humanitarian organisations supporting Syrian refugees in Jordan have conducted needs assessments to direct resources appropriately.

\section{Aims \\ To present a model of psychosocial concerns reported by Syrian refugees and a peer review of research practices.}

\section{Method}

Academic and grey literature databases, the United Nations Syria Regional Response website, key humanitarian organisation websites and Google were searched for needs assessments with Syrian refugees in Jordan between February 2011 and June 2015. Information directly reporting the views of Syrian refugees regarding psychosocial needs was extracted and a qualitative synthesis was conducted.

\section{Results}

Respondents reported that psychological distress was exacerbated by both environmental (financial, housing employment) and psychosocial outcomes (loss of role and social support, inactivity), which are themselves stressors. Need for improvement in research methodology, participatory engagement and ethical reporting was evident.

\section{Conclusions}

Participatory engagement strategies might help to address identified psychosocial outcomes. More rigorous qualitative methods are required to ensure accuracy of findings.

\section{Declaration of interest}

None.

\section{Copyright and usage}

(c) The Royal College of Psychiatrists 2016.
The United Nations (UN) has labelled the current Syrian conflict as the worst humanitarian crisis that has occurred within the first part of the 21st century. ${ }^{1}$ It is estimated that there are in excess of 4 million displaced Syrian refugees in the Middle East and over 629000 who have been displaced to Jordan, ${ }^{2}$ the focus of this review. Although many displaced Syrians live in refugee camps, the largest being Za'atari camp which is home to over 120000 people, the vast majority live in the host community. ${ }^{3}$ In Jordan, people from Syria have limited access to work permits and are often required to work in the informal sector to secure livelihood. Those registered with the UN are eligible to access some cash assistance, food vouchers and education and health systems, ${ }^{4}$ although the health system has struggled to keep up with demand. ${ }^{3}$ Stressors inherent in forced displacement, ${ }^{5}$ combined with exposure to potentially traumatic events (PTEs) during conflict, ${ }^{6}$ are likely to contribute to the development of heightened mental health difficulties in such settings. ${ }^{7,8}$ Over recent years humanitarian organisations have increasingly undertaken psychosocial needs assessments to inform the development of aid programmes. These assessments are of critical importance in that they not only inform policy development but provide early snapshots of the problems experienced by populations subjected to forced displacement. This literature has largely remained unreported in peer-reviewed settings; however, it is important as first-line evidence of psychosocial needs in emerging crises, ${ }^{9,10}$ as well as providing an opportunity for review of the methodological rigour of such assessments. ${ }^{11,12}$

International consensus has identified the most pressing psychosocial research questions within crisis settings as the identification of stressors faced by displaced persons, and how refugee populations perceive and describe their psychosocial concerns. ${ }^{13-16}$ A large number of needs assessments of mental health concerns among Syrian refugees in Jordan have now been undertaken in response to the refugee and humanitarian crisis in that country. A critical factor in reviewing such assessments is assessing the quality of the reports, in relation to both methodological rigour and consideration of ethical research principles. ${ }^{17-19}$ Adherence to qualitative research standards and ethical practice is necessary despite the practical challenges of achieving this in humanitarian aid situations, ${ }^{20}$ with deviation from this likely to undermine the value of the research and potentially undermine relationships between researchers and participants.

This systematic review draws together existing reports of needs assessments undertaken between February 2011 and June 2015 in Jordan, a leading country of first asylum for people fleeing Syria. In reviewing these assessments we aim to create a model of psychosocial concerns identified by Syrian refugees and to subject the design of conducted needs assessments to independent review.

\section{Method}

We undertook a combined search of peer-reviewed academic abstracting databases (PsycINFO, Medline, Scopus, PILOTS, Science Direct and Proquest), grey literature databases (Grey Literature Report, Open Grey and National Repository of Grey Literature), ${ }^{21-23}$ humanitarian organisation websites and also internet searches using the Google search engine (see online Table DS1 for a list of search terms and databases). Searches were conducted in two waves (May 2014 and June 2015). The searches aimed to identify English-language needs assessments that included the terms Syria, refugee and needs assessment between February 2011 and June 2015. Search terms were broad and were varied according to database indexing system and information source. Where available, database subject indexing terms were used to identify relevant articles. Where subject heading results were limited, additional text keyword searches were conducted. Grey literature databases that index documents not published in peer-reviewed journals, such as technical or research reports, 
doctoral dissertations and conference papers, were also searched. The UN Syria Refugee Response interagency information-sharing portal also lists documents shared by UN partner organisations. ${ }^{24}$ All documents from this list, limited to reports conducted in Jordan and written in English, were downloaded. Relevant humanitarian organisation websites were text searched with keywords detailed in online Table DS1, using the Google search engine to limit results to specific websites and portable document format (pdf) documents. For indexed databases, abstracts were downloaded. In all other cases the full text of identified reports was downloaded and individual references created for each document and imported into Endnote in order to remove duplicates. Searches were conducted by the first author (R.W.). This process identified 2256 articles published or released between February 2011 and June 2015, the period reviewed following the mass displacement of Syrian refugees.

\section{Selection process}

Titles and abstracts (if available) of articles were systematically searched for reports of assessments of need, using qualitative or mixed qualitative and quantitative methods, among Syrian people of any age, living in Jordan, displaced by the current crisis. Identified needs assessments were examined by two authors (R.W. and C.L.) to determine if they included psychosocial concerns as reported by the refugees themselves, and agreement reached. For the purpose of this review, psychosocial concerns included distress and symptoms of low mood or anxiety; reported issues resulting from known risk factors for mental health impairment, including gender-based violence, lack of social support, loss of role and conflict-related PTEs; and community desires to build capacity to address psychosocial displacement challenges. Reports based only on data from stakeholders or service providers were not included, unless the informants were explicitly stated to be Syrian refugees. For non-published reports, full reports were text searched for words containing psych, social, support, mental, MHP (abbreviation of MHPSS), or distress. The context of identified words was inspected and reports that directly discussed psychosocial needs identified by Syrian refugees were included. The full text was also visually scanned for sections referring to psychosocial outcomes.

\section{Methodological quality}

The Inter-Agency Standing Committee (IASC) Guidelines on Mental Health and Psychosocial Support in Emergency Settings establish best-practice models for responding to psychosocial needs in humanitarian crises. ${ }^{25,26}$ These guidelines recommend that humanitarian service provision is based on ongoing assessment of the psychosocial concerns of the community, ${ }^{27}$ and recognises that externally driven programmes will not be sustainable. ${ }^{5}$ The guidelines highlight the need to ensure ethical practice, including informed consent and non-expectation of reward for research participation, and participatory engagement and capacity-building practices (hereafter referred to as participatory engagement), which include community stakeholders and training of local staff and volunteers, to facilitate community ownership of programmes, ${ }^{25}$ and to help ensure interventions are ethical and culturally appropriate. ${ }^{5,28}$

We drew on the Cochrane guidelines for inclusion of qualitative research in systematic reviews with assessment quality in four domains: credibility, transferability, dependability and confirmability. ${ }^{29}$ Credibility refers to methods such as member checking (review of emergent themes by research participants or relevant community members), peer debriefing and independent rating, which help ensure that results reflect the views of the participants. Credibility may be enhanced by partnership and engagement. Transferability refers to whether findings can be applied or generalised to other contexts, which is enabled by provision of detailed information about participants and their context. Dependability can be promoted through peer review, debriefing, connection to existing literature, the use of accepted analysis methods and triangulation of data sources. Confirmability may be enhanced by reflexivity regarding the researcher's role, bias, school of thought and impact on the participants and outcomes.

In order to evaluate the methodology of the psychosocial needs assessments we applied existing rating scales, ${ }^{17,30}$ including items from criteria outlined by Blaxter and Popay et $a l,{ }^{19,30}$ with the addition of an item relating to ethical procedures. Reports were scored as low, medium or high ( 0,1 and 2 respectively) on each checklist item. Online Table DS2 outlines the checklist items and the criteria used to score reports at each level. For each methodological domain an average quality score out of 2 was calculated from all scores on items within that domain, and graded as 'does not satisfy minimum criteria' $(<1)$, 'satisfies minimum criteria' $(\geqslant 1)$ or 'high-quality adherence' $(>1.5)$. Report quality indicators for each domain and total score were compared between the two searches using independent means $t$-tests. Significance level was set at $P<0.05$.

\section{Qualitative data synthesis}

In developing a synthesis of needs across assessments, we employed thematic analysis for integrating perceived needs of refugees. ${ }^{18}$ Reports were coded into key themes, which were cross-coded and iteratively revised to identify core themes (online Table DS3). To ensure that findings reflected relevant community attitudes, emerging themes were presented to two Syrian psychiatrists currently treating Syrian refugees in Jordan (A.H.H. and M.A.H.) and were revised accordingly. For themes emerging in at least six articles, the percentage of assessments reporting each theme is given in parenthesis in the section below. As the majority of reports employed open questioning and often did not provide copies of the questions asked of respondents, it was not possible to list the prevalence of those reporting an issue as a percentage of reports that examined that issue. In line with recommendations for psychosocial interventions in post-conflict and mass trauma settings, ${ }^{31,32}$ we distinguished between environmental stressors objective factors that affect access to basic necessities, ${ }^{33}$ such as housing, food, safety, security and rights - and psychosocial impacts, subjectively mediated impacts of environmental stressors, which may themselves become stressors and lead to cycles of resource loss. ${ }^{34}$

\section{Results}

Searches identified 2256 articles. Following removal of 1989 duplicates and exclusions by title, 267 articles were retrieved with 29 meeting inclusion criteria (Fig. 1). The reports are listed in online supplement DS2, and online Table DS4 provides demographic information and report characteristics. Results were reported for a total sample of 15720 refugees in 13 regions of Jordan, including those in refugee camps or host communities, between May 2012 and June 2015. Respondents ranged in age from below 6 years to 85 years and originated from six regions in Syria, most predominantly Deraa, Homs and Damascus. Online Fig. DS1 shows the locations of studies, with most being concentrated in the north of Jordan, and the sample size for each study at each location. The scope of reports varied, with some 


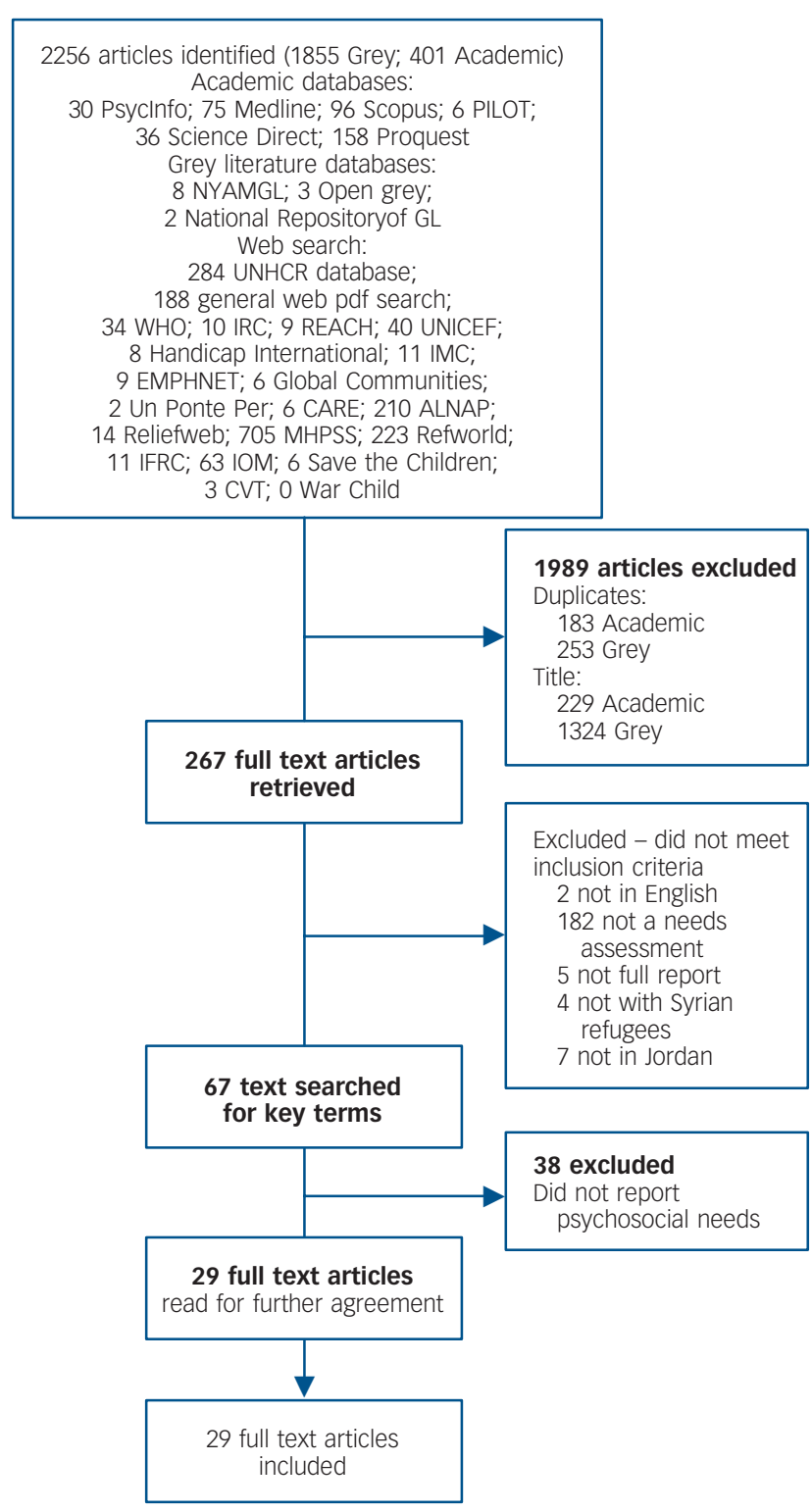

Fig. 1 Flow chart of article selection process. See online Table DS1 for database details.

focusing on specific issues and others only assessing psychosocial issues as part of a larger logistic and operations review. Population-wide psychosocial needs were the primary focus of $17 \%$ of the reports. The remainder of reports that also included a needs assessments were intended to determine current general needs $(31 \%)$, general needs (e.g. housing, food), educational needs $(14 \%)$, health needs $(10 \%)$ or the psychosocial needs of specific subgroups such as women or young people $(28 \%)$, in order to guide immediate aid implementation across a range of domains. Online Table DS4 lists the assessment type of each report.

\section{Synthesis of psychosocial needs}

\section{Environmental stressors}

Insecure housing and lack of income to pay rent was rated as a concern in all reports that assessed this issue (18 reports; $62 \%)$; see online Table DS3 for quotes and exemplars of each theme with individual report numbers listed). Rent costs were reported to be excessive and increasing, ${ }^{35}$ with some households selling food rations to pay rent. ${ }^{35-39}$ Refugees reported living in overcrowded conditions in 9 reports (31\%); for example, up to 18 people in a single home were cited. ${ }^{40}$ Refugees linked cramped living conditions to their psychological health, ${ }^{41}$ and to family conflict. $^{42}$ They reported work exploitation (13 reports; 45\%), including child labour leading to missing school, ${ }^{39,40,43-45}$ and employment restrictions leading to work in the informal sector, ${ }^{39,43,45}$ where they were subjected to long hours, ${ }^{46-48}$ low pay, and abuse and harassment. ${ }^{43,45}$ Difficulties associated with complicated registration processes were reported to limit access to healthcare, ${ }^{49}$ education, ${ }^{50}$ and services. ${ }^{39,51}$ Women reported sexual harassment (17 reports; 59\%), including pressure to accept unwanted marriage proposals, ${ }^{43,45}$ or being asked for sexual favours in exchange for financial aid, ${ }^{44,45}$ with fear of the host community, ${ }^{35,39,45,49,52}$ and movement restrictions (6 reports, $21 \%)$, being reported by women as a result. Eight reports $(28 \%)$ noted that discrimination limited access to healthcare, ${ }^{39,49}$ and to housing; ${ }^{44,52} 13(45 \%)$ reported verbal abuse and insults in public, and 9 (31\%) reported physical abuse in the street, as well as at school for children, resulting in many children leaving education. ${ }^{39,42,43,50,53}$ Approximately half of Syrian children were identified as not attending school. ${ }^{40,43,53}$ In counterbalance, two reports noted positive interactions with the host community. ${ }^{49,52}$

\section{Psychosocial impacts}

Syrian refugees reported that environmental stressors led to psychosocial impacts which themselves created an additional level of stress in 23 reports (79\%). This included loss of social and occupational role (11 reports; $38 \%$ ) and having nothing to do (7 reports; $24 \%$ ), which was identified as contributing to increases in domestic conflict ( 6 reports; $21 \%$ ). Respondents reported social isolation due to loss of contact with social support structures and fear of abuse outside the home in 15 reports (52\%). Isolation was reported to be worse in the host community, ${ }^{40,42}$ with limited spaces for social engagement. ${ }^{41,51,54}$ Many could not afford hospitality and feared being a burden on others if they visited them. ${ }^{46,47}$

\section{Symptoms of distress}

Being worried or distressed by practical circumstances and uncertainty was commonly reported (24 reports; $83 \%$ ). In 15 reports (52\%), Syrian refugees identified that PTEs (e.g. war and displacement related) had led to symptoms of distress, ${ }^{43,45,49,52}$ including anger, ${ }^{43,52,55}$ and increased general fear. ${ }^{42,53}$ They reported being frightened by reminders of PTEs, including the sounds of aircraft, guns or firecrackers (7 reports; 39\%) and avoiding them. ${ }^{55}$ Parents and children reported distress and fear about family separation (7 reports; $24 \%$ ). Children reported fears of burning, being arrested, being shot or kidnapped. ${ }^{41}$ Symptoms of depression and low mood were also commonly reported (20 reports; 69\%), including symptoms of sadness, ${ }^{39,40,45,50,52,55}$ hopelessness, ${ }^{43,47,52,53,55}$ lethargy, ${ }^{54}$ loss of interest, ${ }^{44,55,56}$ insomnia, ${ }^{36,37,46,47,52}$ impaired concentration, ${ }^{47,52-55}$ suicidal ideation, ${ }^{37,47,57,58}$ and self-harm. ${ }^{42}$ One report noted deterioration in psychological symptoms in surveys that spanned multiple time assessments. $^{35}$

\section{Interactions with stressors}

Refugees reported that psychological symptoms interacted with the other displacement stressors and often led to anger (10 reports; $34 \%$ ), further exacerbating familial distress. ${ }^{36}$ Inactivity, loss of role and psychological symptoms were perceived to be leading to aggressive behaviour among young men in the camp 
setting (8 reports; 27\%). Adults linked children's aggressive behaviour to psychological problems. ${ }^{42,52,59}$ Violence within the refugee community was another reason for children not attending school. ${ }^{35,59,60}$ The stresses of life in displacement, especially inactivity, ${ }^{35,56}$ were seen as leading to family conflict and domestic violence in 14 reports (48\%), which was reported to be common, ${ }^{40,42,50,55}$ and increasing. ${ }^{45,47,48,52,61}$ In one report $38 \%$ of Syrians reported child abuse in the family. ${ }^{58}$

\section{Psychosocial support services}

Groups in 11 reports (38\%) asked for increases in psychosocial support services and community activities to relieve stress. Many highlighted satisfaction with the range of activities available at informal education centres, preferring them to schools, ${ }^{50,53}$ whereas others commented that there were many activities for girls but not for boys. ${ }^{37,56}$ Victims of conflict-related and familial gender-based violence were reported to be prevented from seeking physical or psychological care owing to stigma and safety fears, ${ }^{37-39,48}$ or lack of information. ${ }^{44}$ There was recognition of the problem of gender-based violence across reports, $37-39,44,45,48,59$ with young men requesting awareness sessions to reduce domestic violence. ${ }^{56}$ Young women also requested awareness sessions regarding early marriage, ${ }^{38}$ and there was social action by groups of women participating in public performances exploring this issue. ${ }^{60}$ The refugees displayed a desire to be involved in the process of community support or activities that could mobilise social resources (11 reports; $38 \%$ ) and requested skills development (6 reports; 21\%), including psychosocial care skills and legal procedures. ${ }^{39,50}$ Many highlighted the benefits of informal community supports, ${ }^{44}$ and self-directed participatory engagement in community life, ${ }^{45,53}$ including kin caring for children separated from their parents, ${ }^{40}$ and children requesting the chance to help others. ${ }^{62}$ Refugees also reported that their offers to volunteer or provide feedback were ignored by humanitarian organisations. ${ }^{39,41,48}$ Syrian volunteer teachers expressed frustration at not being permitted a greater role in the education of children in Za'atari camp, ${ }^{59}$ even though children said they preferred Syrian teachers. ${ }^{53}$

\section{Evaluation of report quality}

Table 1 outlines the findings of the methodology review for the 29 psychosocial assessments. For each of the five domains a quality score out of 2 was derived. This represents an average across all 29 reports for each of the domains. A score for a domain of less than 1.0 indicates the reports did not satisfy minimum criteria for that domain; a score of 1.0-1.5 means minimum criteria were met (medium quality) and a score above 1.5 indicates that the majority of reports met the majority of criteria for that domain (high quality). For each quality checklist item the percentage of reports employing a minimum level of rigour were defined as those that met either medium- or high-quality concordance ratings across each of the checklist items. The table also presents the percentage of reports meeting the highest quality ranking for each item. A copy of the individual scores for each needs assessment is available from the authors. Dependability scores (see definition above) on average satisfied minimum criteria (average 1.1 across reports and criteria). Most reports (90\%) reviewed relevant literature (59\% high quality) with $93 \%$ of reports also using some form of triangulation of multiple data sources (62\% high); $72 \%$ of reports used trained staff or provided training to staff ( $24 \%$ high) and $72 \%$ described data collection and analysis procedures ( $45 \%$ high). However, only $41 \%$ described the qualitative data analysis techniques applied (31\% high) and only $45 \%$ used supervision or debriefing procedures (24\% high). On

\begin{tabular}{|c|c|c|c|}
\hline \multirow[b]{2}{*}{ Criteria } & \multirow{2}{*}{$\begin{array}{c}\text { Mean score } \\
(0-2)\end{array}$} & \multicolumn{2}{|c|}{$\begin{array}{c}\text { Reports } \\
\text { achieving score, \% }\end{array}$} \\
\hline & & $\geqslant 1.0$ & $\geqslant 1.5$ \\
\hline Dependability & 1.1 & 34 & 24 \\
\hline Review of literature & 1.5 & 31 & 59 \\
\hline Clear accounts of data collection & & & \\
\hline and analysis & 1.2 & 28 & 45 \\
\hline Training provided or trained staff & 1.0 & 48 & 24 \\
\hline Supervision or peer debriefing & 0.7 & 21 & 24 \\
\hline Qualitative analysis procedures & 0.7 & 10 & 31 \\
\hline Triangulation & 1.6 & 31 & 62 \\
\hline Transferability & 1.4 & 34 & 45 \\
\hline Clear accounts of sampling & 1.3 & 21 & 55 \\
\hline Purposive sampling & 1.2 & 10 & 55 \\
\hline Adequate description & 1.5 & 28 & 62 \\
\hline Data is contextualised & 1.4 & 34 & 55 \\
\hline Confirmability & 1.0 & 31 & 24 \\
\hline Adapt design to context & 1.1 & 24 & 41 \\
\hline Discussion of tools & 1.2 & 34 & 41 \\
\hline Reflexivity or bias & 0.8 & 21 & 28 \\
\hline Credibility & 0.8 & 28 & 14 \\
\hline Member checking & 0.4 & 10 & 17 \\
\hline Privileges knowledge & & & \\
\hline of respondents & 1.4 & 28 & 59 \\
\hline Participatory & 0.6 & 10 & 24 \\
\hline Ethics & 1.0 & 0 & 0 \\
\hline Ethics statement & 1.0 & 7 & 45 \\
\hline
\end{tabular}

average, transferability scores satisfied minimum criteria (average score across reports and criteria 1.4). Most (90\%) placed the findings reported in the relevant context (55\% high); $90 \%$ of reports provided adequate description of research setting (55\% high); $76 \%$ gave clear accounts of sampling (55\% high) and $66 \%$ used purposive sampling to target specific groups (55\% high).

Confirmability scores on average also satisfied minimum criteria (average 1). Half (48\%) of reports included researcher reflexivity (28\% high); three-quarters $(76 \%)$ discussed the impact of tools employed (41\% high) and two-thirds $(66 \%)$ reported adapting research tools to the local context ( $41 \%$ high). On average, credibility, partnership and engagement scores across the reports did not meet minimum criteria (average 0.8). Although $86 \%$ of reports privileged the knowledge of refugees over other sources within qualitative analysis (59\% high), only a third of needs assessments (34\%) used some form of participatory engagement to ensure the inclusion of refugees within research design and implementation (24\% high) and only $28 \%$ of reports used member checking procedures to confirm findings (17\% high). In terms of ethical practices, on average reports did not meet minimum criteria (average 0.9 ); $52 \%$ of reports described ethical procedures ( $44 \%$ high). There was considerable improvement from the first systematic search (2014) to the second (2015), with significant differences between the two searches in dependability $(t(27)=2.2, P=0.04)$, confirmability $(t(27)=2.2$, $P=0.04)$ and total quality score $(t(27)=2.4, P=0.03)$.

\section{Discussion}

Across the surveys reviewed, Syrian refugees living in Jordan reported distress as a direct result of both PTEs and stressors inherent in the displacement setting. These factors interact to exacerbate distress. Despite the stigma associated with mental healthcare-seeking documented among Syrian populations, ${ }^{9,63}$ substantial numbers of displaced Syrian people in Jordan identified 
the impact of stressors on mental health difficulties within the community across the majority of the needs assessments undertaken, and a proportion requested access to psychosocial support. It is unclear if this represents a cultural shift in attitudes to mental healthcare or has spontaneously arisen from the experiences of the refugees, especially considering that only $17 \%$ of the needs assessment reports were explicitly focused on assessing psychosocial needs.

Figure 2 depicts a model derived from the current findings. Consistent with Miller \& Rasmussen, ${ }^{7}$ this model describes how PTEs during conflict and/or displacement exert a direct effect on psychological symptoms, whereas displacement stressors mediate the effect of PTEs on psychological symptoms. In addition, as demonstrated in other post-conflict settings, ${ }^{64}$ the importance of anger responses arising from PTEs and socioeconomic stressors is also highlighted. Previous research has demonstrated that exposure to PTEs has a direct effect on anxiety and mood symptoms. ${ }^{6}$ The interaction of environmental stressors and psychosocial outcomes worsens psychological symptoms and daily functioning, ${ }^{7,9}$ making it harder to work. ${ }^{65}$ Environmental stressors, such as lack of employment rights, ${ }^{66}$ affect mental health outcomes, ${ }^{67}$ and produce psychosocial outcomes that themselves become stressors, such as social isolation. ${ }^{34}$ Loss of social support increases feelings of loneliness, worsening symptoms of depression, ${ }^{68}$ further isolating those most in need of help. Finally, reactions to PTEs and displacement stressors lead to increased anger and aggression. ${ }^{9,64}$ The interaction of PTEs, environmental stressors and psychosocial outcomes creates continuous feedback, reinforcing mental health impairment in the absence of protective factors. In line with best practice models for psychosocial interventions in humanitarian aid settings, ${ }^{25,31,32}$ interventions that might alleviate this burden and the stage at which they might have the most effect are also depicted in the model. The importance of basic needs provision is evident in that such essential services directly alleviate environmental stressors. Specialist and non-focused mental health services may ameliorate psychological symptoms, but these effects are unlikely to be fully effective or to meet the broader needs of the refugees in the absence of psychosocial (or social) ${ }^{69}$ programmes to target psychosocial stressors or limited resources to reduce environmental stressors. ${ }^{25,70}$ The two types of psychosocial interventions requested by refugees - community group programmes and participatory engagement in the relief effort - are well suited to addressing identified psychosocial impacts, ${ }^{32}$ can be made available to large numbers of people and can promote sustainability. ${ }^{31,66,69}$

Silove argues that challenges to identity and role as well as bonds and networks in displacement, including discrimination and social isolation, contribute to poor mental health outcomes, and links this with family difficulties. ${ }^{31} \mathrm{He}$ calls for programmes that promote access to education, employment and community participation. An increased role for refugees in the administration of social and community programmes (i.e. participatory engagement) could promote social networks, sustainability and community ownership of projects, ${ }^{5,66}$ while enabling activity, forging new social roles, skills sharing and acquisition. ${ }^{28}$ Increased refugee involvement in the design and implementation of psychosocial programmes might address many of the key psychosocial outcomes identified in our review, ${ }^{32}$ and was noted as a key strength of the psychosocial needs assessments that used participatory engagement with refugee communities. It appears that humanitarian organisations can improve participatory engagement by involving local stakeholders as organisers and as research or programme partners. ${ }^{11}$ Attention to the manner in which services are provided, through consultation and active engagement, can help address these needs while maintaining a focus on basic services and security. ${ }^{25}$ Considering the potential for participatory engagement to help overcome the effects of structural power inequalities on human dignity and agency, and the fact that it is being requested, an increase in these strategies is strongly advised. ${ }^{66}$ Limited employment rights for Syrians in Jordan make it difficult for humanitarian organisations to formally involve grassroots Syrian organisations in project planning, yet there is growing evidence that refugees in urban settings can make positive contributions to local economies while supporting their own livelihoods. ${ }^{71}$ International humanitarian organisations may be in a position to promote this.

In contrast, the implementation of needs assessments reviewed here demonstrated a general lack of engagement with participatory research methods. The absence of strategies to include refugees as key members of research teams limits opportunities for these people to contribute to the knowledge that will influence what happens to them. There were some notable exceptions to this:

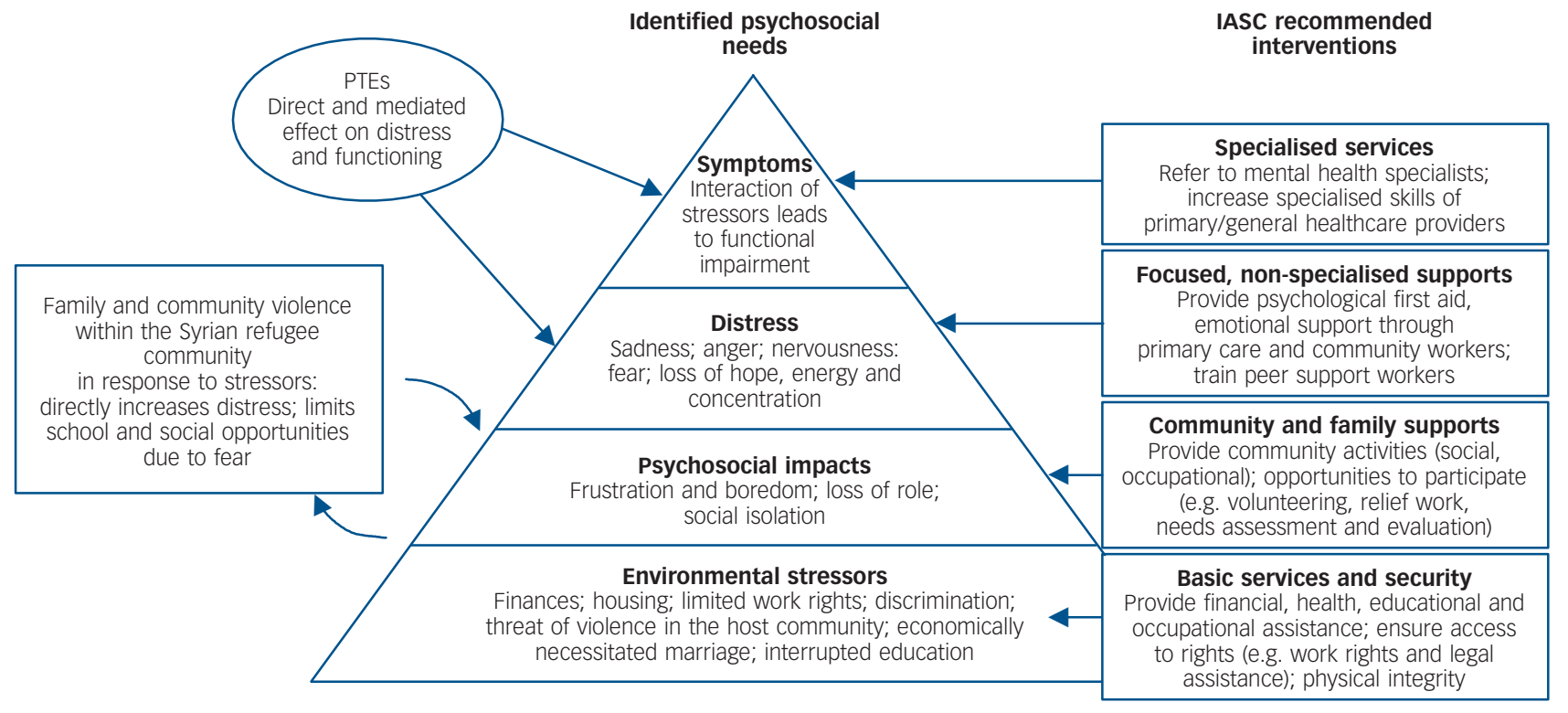

Fig. 2 Model of psychosocial concerns raised by Syrian refugees. IASC, Inter-Agency Standing Committee; PTE, potentially traumatic event. 
for example, a World Vision report was written entirely by Syrian refugee children. ${ }^{62}$ Integration of participatory models might also assist with addressing key methodological weaknesses of the needs assessments reviewed here by building member checking procedures into the research process.

\section{Report quality}

As noted in other contexts, ${ }^{9}$ the use of methods to improve the validity of psychosocial needs assessments was mixed, with adherence to some methodological standards such as the inclusion of literature reviews, privileging of refugee respondents and triangulation of qualitative data, but generally poor adherence to the many other quality indicators. The danger of such deviation from quality standards is that reports may not provide the accurate information needed for effective programme planning and resource allocation. ${ }^{19}$ For example, many reports used the word 'trauma' to refer to PTEs; it was not clear whether this term accurately reflected the views expressed by respondents or the orienting framework adopted by the humanitarian organisations. Greater reflexivity would have helped to clarify this issue. Credibility or refugee engagement scores did not meet minimum criteria, in particular because member checking and participatory techniques were rarely employed, as noted above. Greater inclusion of first-person exemplars would aid understanding of refugee perspectives and contexts. Transferability scores satisfied minimum criteria, indicating that most assessment teams considered the impact of sampling and the need to provide relevant contextual information. Convenience sampling may have biased results towards care-seeking refugees. In addition, many reports focused on the needs of specific vulnerable groups (e.g. women), resulting in limited information on the views of other groups (e.g. men), preventing a holistic or systemic approach to social problems such as gender-based violence. ${ }^{5}$

Confirmability scores only marginally satisfied minimum criteria; although many humanitarian organisations adapted and discussed research tools, there is room for improvement in the areas of researcher reflexivity and engagement with methods to address potential sources of bias. The perspectives of research organisations must be taken into account when interpreting qualitative results. ${ }^{5}$ For example, many international humanitarian organisations adopt an official stance of neutrality which may influence the reporting of and questioning about sensitive political issues, despite their likely relevance to psychosocial stress. Considering that most of the participants were recipients of aid from the organisations conducting the research, the way that researcher-participant power dynamics influenced the responses, and how this issue might be mitigated, should be important topics for consideration. The impact of questions asked should also be reviewed. For example, terms such as 'psychosocial' may not translate well into Arabic, so direct questions relating to these concerns may result in less reporting than free-listing. ${ }^{41,51}$ Dependability scores satisfied minimum criteria. Although many assessment teams used triangulation of multiple data sources, qualitative analysis techniques were generally not described. These are all basic qualitative methods that should be reported and included as standard procedure to enhance rigour. ${ }^{19,29,30,72,73}$ The low engagement with ethical reporting issues in assessments indicates that there is limited expectation in the field for organisations to be transparent and accountable regarding the potential for ethical and rights violations during research practice, despite clear recommendations laid out in the IASC guidelines. Considering the lack of legal protection and information provision available to refugees in humanitarian aid contexts, it is important that these guidelines are adhered to in the absence of peer review and human research ethics approval processes. Consistent with IASC guidelines, ${ }^{25}$ agencies should report on procedures for informed consent, ensuring participants understand confidentiality, do not expect rewards for participation and are aware of the voluntary nature of participation in research as a minimum requirement. ${ }^{5,74}$ There are ample open source tools and guidelines available to organisations to aid with appropriate ethical adherence and reporting. ${ }^{25,27}$ The expectation of clear ethical procedures should help to ensure their use in the field.

\section{Study limitations}

The search terms used to identify reports were intentionally broad. However, since most unpublished literature sources were not indexed, requiring basic text searches, and unpublished reports did not have abstracts describing relevant inclusion or exclusion criteria, some potentially relevant assessments may have been excluded or not identified. As only English-language reports were included, some reports in other languages such as Arabic may have been excluded. However, only two non-English language reports were excluded during the search. Percentages listed should not be taken to indicate the prevalence of opinions or themes in the community, as the refugees were not systematically asked questions relating to themes across studies. As reports were not peer-reviewed and were intended for immediate programme implementation, authors might not have deemed it necessary to include details of methods used within reports. Last, the perspective of the first author should be acknowledged: R.W. has run both research and psychosocial group programmes with Syrian refugees in Jordan, both of which involved large participatory elements. During these programmes the capacity and desire of community members to direct programme implementation was evident. This may have resulted in bias when interpreting the reports.

\section{Study implications}

We have identified an urgent need for humanitarian organisations undertaking needs assessments with refugees to improve their use of rigorous qualitative research and ethical best practice guidelines in order to ensure that the perspectives of potential aid recipients are more clearly represented. Despite this limitation, the collective findings of the 29 reports reviewed indicate that many displaced Syrians living in Jordan identify the interacting impact of displacement stressors and mental health impairment and indicate a willingness to participate in programmes aimed at addressing such mental health issues. Psychosocial impacts, such as loss of role and social support, are key areas for which humanitarian organisations can employ participatory engagement strategies to improve relevance and sustainability. ${ }^{25}$

\section{Ruth Wells, BSC, University of Sydney, Australia; Zachary Steel, PhD, MClinPsych, School of Psychiatry, University New South Wales, The Black Dog Institute, Hospital Road, Prince of Wales Hospital, New South Wales, Australia; Mohammad Abo Hilal MD, Syria Bright Future; Abdulhalim Hasan, MD, American Medical Center, Erbil, Iraq; Catalina Lawsin, PhD, Department of Behavioral Sciences, RUSH Medical Center, Chicago, USA}

Correspondence: Ruth Wells, Level 2 (M02F), 94 Mallett St, Camperdown, NSW 2050, Australia. Email: rwel3411@uni.sydney.edu.au

First received 13 Feb 2015, final revision 13 Aug 2015, accepted 27 Oct 2015

\section{References}

1 The Lancet. The war on Syrian civilians. Lancet 2014; 383: 383.

2 United Nations High Commissioner for Refugees. Syria Regional Response Plan. UNHCR, 2015 (http://data.unhcr.org/syrianrefugees/regional.php). 
3 Murshidi MM, Hijjawi MQ, Jeriesat S, Eltom A. Syrian refugees and Jordan's health sector. Lancet 2013; 382: 206-7.

4 Syria Needs Analysis Project. Legal Status of Individuals Fleeing Syria. Assessment Capacities Project, 2013.

5 Wessells MG. Do no harm: toward contextually appropriate psychosocial support in international emergencies. Am Psychol 2009; 64: 842-54.

6 Steel Z, Chey T, Silove D, Marnane C, Bryant A, van Ommeren N. Association of torture and other potentially traumatic events with mental health outcomes among populations exposed to mass conflict and displacement: a systematic review and meta-analysis. JAMA 2009; 302: 537-49.

7 Miller KE, Rasmussen A. War exposure, daily stressors, and mental health in conflict and post-conflict settings: bridging the divide between traumafocused and psychosocial frameworks. Soc Sci Med 2010; 70: 7-16.

8 Charlson FJ, Steel Z, Degenhardt L, Chey T, Silove D, Marnane C, et al. Predicting the impact of the 2011 conflict in Libya on population mental health: PTSD and depression prevalence and mental health service requirements. PLOS One 2012; 7: e40593.

9 Quosh C, Eloul L, Ajlani R. Mental health of refugees and displaced persons in Syria and surrounding countries: a systematic review. Intervention 2013; 11 276-94

10 Tol WA, Barbui C, Galappatti A, Silove D, Betancourt TS, Souza R, et al. Mental health and psychosocial support in humanitarian settings: linking practice and research. Lancet 2011; 378: 1581-91.

11 Ager A, Burnham G, Checchi F, Gayer M, Grais RF, Henkens M, et al. Strengthening the evidence base for health programming in humanitarian crises. Science 2014; 345: 1290-2.

12 Tol WA, Patel V, Tomlinson M, Baingana F, Galappatti A, Silove D, et al. Relevance or excellence? Setting research priorities for mental health and psychosocial support in humanitarian settings. Harv Rev Psychiatry 2012; 20 25-36.

13 World Health Organization. Assessing Mental Health and Psychosocial Needs and Resources: Toolkit for Major Humanitarian Settings. WHO, 2012.

14 Inter-Agency Standing Committee Reference Group for Mental Health and Psychosocial Support in Emergency Settings. IASC Reference Group Mental Health and Psychosocial Support Assessment Guide. IASC, 2012.

15 United Nations High Commissioner for Refugees. Participatory Assessment in Operations. UNHCR, 2006.

16 Tol WA, Patel V, Tomlinson M, Baingana F, Galappatti A, Panter-Brick C, et al Research priorities for mental health and psychosocial support in humanitarian settings. PLOS Med 2011; 8: 1182.

17 Evans D, Pearson A. Systematic reviews of qualitative research. Clin Eff Nurs 2001; 5: 111-9.

18 Braun V, Clarke V. Using thematic analysis in psychology. Qual Res Psychol 2006; 3: 77-101.

19 Blaxter M. Criteria for the evaluation of qualitative research papers. Med Sociol News 1996; 22: 4-7.

20 Inter-Agency Standing Committee Reference Group for Mental Health and Psychosocial Support in Emergency Settings. Recommendations for Conducting Ethical Mental Health and Psychosocial Research in Emergency Settings. IASC, 2014.

21 Myohanen L, Taylor E, Keith L. Accessing grey literature in public health: New York Academy of Medicine's Grey Literature report. Publ Res Q 2005; 21: $44-52$.

22 Schopfel J, Prost H. Document supply of grey literature and open access: an update. Interlend Doc Supply 2009; 37: 181-91.

23 National Technical Library. National Repository of Grey Literature. University of. Economics, Prague, National Technical Library, Academy of Sciencies of the Czech Republic, University of South Bohemia in Ėeské Budějivoce, 2014 (http://roar.eprints.org/3496/).

24 United Nations High Commissioner for Refugees. Syria Regional Refugee Response. UNHCR (http://data.unhcr.org/syrianrefugees/ country. php?id = 107).

25 Inter-Agency Standing Committee. IASC Guidelines on Mental Health and Psychosocial Support in Emergency Settings. IASC, 2007.

26 United Nations High Commissioner for Refugees. Operational Guidance for Mental Health and Psychosocial Support Programming for Refugee operations. UNHCR, 2013.

27 World Health Organization, King's College London. The Humanitarian Emergency Settings Perceived Needs Scale (HESPER): Manual with Scale: 89. WHO, 2011.

28 Taleb ZB, Bahelah R, Fouad FM, Coutts A, Wilcox M, Maziak W. Syria: health in a country undergoing tragic transition. Int J Public Health 2015; 60 (suppl 1): 63-72.
29 Hannes K. Critical appraisal of qualitative research. In Supplementary Guidance for Inclusion of Qualitative Research in Cochrane Systematic Reviews of Interventions (eds J Noyes, A Booth, K Hannes, et al): 1-14. Cochrane Collaboration Qualitative Methods Group, 2011.

30 Popay J, Rogers A, Williams G. Rationale and standards for the systematic review of qualitative literature in health services research. Qual Health Res 1998; 8: 341-51

31 Silove D. The ADAPT model: a conceptual framework for mental health and psychosocial programming in post conflict settings. Intervention 2011; 11: 237-48.

32 Hobfoll SE, Watson P, Bell CC, Bryant RA, Brymer MJ, Friedman MJ, et al. Five essential elements of immediate and mid-term mass trauma intervention: empirical evidence. Psychiatry 2007; 70: 269-83.

33 Ryan D, Dooley B, Benson C. Theoretical perspectives on post-migration adaptation and psychological well-being among refugees: towards a resource-based model. J Refug Stud 2008; 21: 1-18.

34 Hobfoll SE. The influence of culture, community, and the nested-self in the stress process: advancing conservation of resources theory. Appl Psychol 2001; 50: 337-421.

35 Care Jordan. Lives Unseen: Urban Syrian Refugees and Jordanian Host Communities Three Years into the Syrian Crisis. Care Jordan, 2014.

36 Questscope. Participatory Reflection and Action (PRA) Report. Factors Affecting the Education Situation of Syrian Refugees in Jordan. Questscope, 2013.

37 International Rescue Committee. Jordan Country Program Cross-Sectoral Assessment of Syrian Refugees in Urban Areas of South and Central Jordan. IRC, 2013.

38 United Nations High Commissioner for Refugees. Report of the Participatory Assessment UNHCR, Amman December 2012. UN, 2012.

39 Serrato BC. Refugee Perceptions Study. Za'atari Camp and Host Communities in Jordan. Oxfam, 2014.

40 Save the Children, King Hussein Foundation Information and Research Centre. Kinship Care Report. Syrian Refugee Children in Jordan. Save the Children, 2015.

41 International Medical Corps. Rapid Camp Assessment: Improving the Well-Being of Syrians in Za'atari. IMC, 2012.

42 UK Aid, UNICEF, International Medical Committee. Mental Health Psychosocial and Child Protection for Syrian Adolescent Refugees in Jordan. 2014.

43 Mercy Corps. Syrian Adolescents: Their Tomorrow Begins Today. Mercy Corps, 2014.

44 United Nations High Commissioner for Refugees. Woman Alone. The Fight For Survival by Syria's Refugee Women. UN, 2014.

45 International Rescue Committee. Are We Listening? Acting on our Commitments to Women and Girls Affected by the Syrian Conflict. IRC, 2014.

46 Care Jordan. Baseline Assessment of Community Identified vulnerabilities among Syrian Refugees living in Amman. Rapid Participatory Community Assessment. Care Jordan, 2012.

47 Care Jordan. Syrian Refugees in Urban Jordan. Baseline Assessment of Community-Identified Vulnerabilities Among Syrian Refugees Living in Irbid, Madaba, Mufra, and Zarqa. Care Jordan, 2013.

48 Doedens W, Giga N, Krause S, Onyango MA, Sami S, Stone E, et al. Reproductive Health Services for Syrian Refugees in Zaatri Refugee Camp and Irbid City, Jordan An Evaluation of the Minimum Initial Service Package. Boston University School of Public Health, UN Population Fund, US Centers for Disease Control and Prevention, and Women's Refugee Commission, 2013.

49 United Nations High Commissioner for Refugees, UNFPA, International Medical Corps. Population-based health access assessment for Syrian refugees in non-camp settings throughout Jordan: with sub-investigation on non-communicable disease management. A qualitative cross-sectional cluster survey. UN, 2014.

50 Joint Education Needs Assessment Education Sector Working Group. Access to Education for Syrian Refugee Children and Youth in Jordan Host Communities. Joint Education Needs Assessment Report. JENA, 2015.

51 Un Ponte Per. Comprehensive Assessment on Syrian Refugees Residing in the Community in Northern Jordan. UPP, 2012.

52 Ministry of Health Jordan, Aide Medicale Internationale. Hashemite Kingdom of Jordan Syrian Crisis Health Needs Assessment. Report to the Ministry of Health. 2014.

53 Joint Education Needs Assessment (JENA) Education Sector Working Group. Access to Education for Syrian Refugee Children in Zaatari Camp, Jordan. JENA, 2014. 
54 Handicap International, HelpAge International. Hidden Victims of the Syrian Crisis: Disabled, Injured and Older Refugees. Handicap International, HelpAge International, 2014.

55 World Health Organization, International Medical Corps, Jordanian Ministry of Health. Assessment of Mental Health and Psychosocial Support Needs of Displaced Syrians in Jordan. WHO, 2015.

56 United Nations High Commissioner for Refugees. Participatory Needs Assessment EJC Refugee Camp November 2013. UN, 2013.

57 Jordan Health Aid Society. Displaced Syrians in Jordan: A Mental Health and Psychosocial Information Gathering Exercise. Analysis and Interpretations of Findings. Jordan Health Aid Society, 2012.

58 International Medical Committee, UNICEF. Mental Health/Psychosocial and Child Protection Assessment for Syrian Refugee Adolescents in Za'atari Refugee Camp, Jordan July 2013. IMC, 2013.

59 Joint Education Needs Assessment (JENA) Task Force, Education Sector Working Group. Joint Education Needs Assessment. Za'atari Refugee Camp. JENA, 2013.

60 Women's Refugee Commission. Unpacking Gender: The Humanitarian Response to the Syrian Refugee Crisis in Jordan. WRC, 2014.

61 International Rescue Committee. Assessment Report Cash Transfer Program to Syrian Refugees in Jordan. IRC, 2012.

62 World Vision. Children's Report. Stand with Me. Our Uncertain Future. World Vision, 2014

63 Maziak W, Asfar T, Mzayek F, Fouad FM, Kilzieh N. Socio-demographic correlates of psychiatric morbidity among low-income women in Aleppo, Syria. Soc Sci Med 2002; 54: 1419-27.

64 Brooks R, Silove D, Steel Z,Steel CB, Rees S. Explosive anger in postconflict Timor Leste: interaction of socio-economic disadvantage and past human rights-related trauma. J Affect Disord 2011; 31: 268-76.
65 Al-Hamzawi AO, Rosellini AJ, Lindberg M, Petukhova M, Kessler RC, Bruffaerts R. The role of common mental and physical disorders in days out of role in the Iraqi general population: results from the WHO World Mental Health Surveys. J Psychiatr Res 2014; 53: 23-9.

66 Quosh C. Mental health, forced displacement and recovery: integrated mental health and psychosocial support for urban refugees in Syria. Intervention 2013; 11: 295-320.

67 Silove D, Steel Z, Susljik I, Frommer N, Loneragan C, Chey T, et al. The impact of the refugee decision on the trajectory of PTSD, anxiety, and depressive symptoms among asylum seekers: a longitudinal study. Am J Disaster Med 2007; 2: 321-9.

68 Cummings S, Sull L, Davis C, Worley N. Correlates of depression among older Kurdish refugees. Soc Work 2011; 56: 159-68.

69 Van Ommeren M, Saxena S, Saraceno B. Mental and social health during and after acute emergencies: emerging consensus? Bull WHO 2005; 83: 71-5.

70 Bou Khalil R. Where all and nothing is about mental health: beyond posttraumatic stress disorder for displaced Syrians. Am J Psychiatry 2013; 170: $1396-7$.

71 Jacobsen K. Refugees and asylum seekers in urban areas: a livelihoods perspective. J Refug Stud 2006; 19: 273-86.

72 Critical Appraisal Skills Program. Qualitative Research Checklist. CASP, 2013.

73 Bearman M, Dawson P. Qualitative synthesis and systematic review in health professions education. Med Educ 2013; 47: 252-60.

74 Mackenzie C, McDowell C, Pittaway E. Beyond 'do no harm': the challenge of constructing ethical relationships in refugee research. J Refug Stud 2007; 20: 299-319.

(A) EXTRA 